\title{
Membaca Berkelompok Kasus: Pemelajar Bahasa Jepang Orang Indonesia
}

\author{
Arianty Visiaty \\ Program Studi Sastra Jepang, Fakultas Sastra \\ Universitas Al Azhar Indonesia, Jl. Sisingamangaraja, Jakarta 12110 \\ E-mail: ariantyvisiaty@uai.ac.id
}

\begin{abstract}
Abstrak - Keterampilan membaca yang baik diperlukan untuk membuat skripsi. Mahasiswa tidak hanya diharapkan bisa membaca bibliografi berbahasa Inggris, tetapi juga bahasa Jepang. Akan tetapi bagi mahasiswa pemelajar bahasa Jepang yang berasal dari negara yang beraksara non-kanji, membaca bahan bacaan otentik seperti buku, koran, ataupun dokumen lainnya bukanlah hal yang mudah (terutama untuk pemelajar tingkat menengah). Fokus dari penelitian ini adalah mutual activity yang terjadi di kegiatan membaca berkelompok dan penggunaan prior knowledge. Hasil dari penelitian ini adalah mahasiswa dapat menangkap isi bacaan otentik dalam bahasa Jepang di atas level kemampuannya. Dengan membaca dalam kelompok, mahasiswa bisa saling menggunakan sumber daya yang mereka miliki sehingga mereka bisa mengerti isi bacaan lebih dalam. Dengan menggunakan bahasa ibu, mahasiswa dapat dengan mudah menggunakan prior knowledge untuk memahami isi bahan bacaan, dan dapat saling bertanya dan memberikan pendapat secara bebas.
\end{abstract}

Abstract - To write a good thesis, students must have good reading skills. In the Japanese Language learner case, he/she will be required to be able to read not only textbooks or other written sources in Indonesian language and English, but also materials in Japanese. But, to Japanese language learners that come from nonkanji countries, reading authentic materials such as books, news papers, documents, etc., is not easy (more especially for intermediate level learners). The focus of this study is the mutual activity that occurs and the use of prior knowledge on group reading. The outcome of this research is that students are able to grasp authentic reading content in Japanese that is in a level that is beyond their actual ability level. By reading in groups, students can one another use resources that they each have so that their understanding towards the reading content is deeper. By using the mother language, students are easily able to raise and use their prior knowledge to understand reading materials, can ask questions towards one another, express opinions and freely have a debate.

Keywords - Group reading, Mutual activity, Prior knowledge, Mother tongue

\section{PENDAHULUAN}

$\mathrm{M}$ enulis skripsi adalah salah satu syarat kelulusan bagi mahasiswa bahasa Jepang yang belajar di sebagian besar universitas di Indonesia. Untuk menulis skripsi yang baik diperlukan kemampuan membaca yang baik pula. Tidak hanya kemampuan membaca buku-buku atau sumber acuan berbahasa Indonesia atau Inggris, tetapi juga yang berbahasa Jepang.

Akan tetapi bagi mahasiswa bahasa Jepang yang bukan dari negara beraksara kanji (untuk selanjutnya disebut sebagai mahasiswa/pemelajar non-kanji), membaca bahan acuan berupa buku, jurnal, dokumen, koran, dll, (untuk selanjutnya disebut sebagai bahan bacaan otentik) berbahasa Jepang tidak mudah. Hal ini dikarenakan struktur kalimat dari bahan bacaan otentik yang rumit, dan banyaknya kosakata, tata bahasa, maupun kanji yang belum diketahui oleh mahasiswa.

Membaca bahan acuan perlu dibimbing dari tingkat menengah. Agar mahasiswa bahasa Jepang tingkat menengah dapat membaca bahan bacaan otentik perlu dilakukan metode yang khusus. 
Salah satu cara agar mahasiswa dapat membaca bahan bacaan otentik adalah dengan membaca berkelompok. Dengan membaca berkelompok mahasiswa diharapkan dapat saling menggunakan sumber daya (resource) yang ada pada masingmasing, sehingga dapat saling melengkapi pemahaman terhadap isi bacaan.

\section{KERANGKA TEORI / TINJAUAN PUSTAKA}

Peer Reading adalah kegiatan memahami bacaan dengan saling membantu menyelesaikan masalah membaca secara berdialog bersama teman (Tateoka, 2005). Kegiatan ini bisa dilakukan berdua atau lebih dari dua orang. Penelitian mengenai kegiatan peer reading dalam bahasa Jepang dilakukan oleh Tateoka (2000). Tateoka melakukan penelitian dengan membuat kegiatan membaca berpasangan (peer reading).

Target penelitiannya adalah pemelajar bahasa Jepang sebanyak 2 orang. Ke dua pemelajar tersebut telah lulus ujian kemampuan bahasa Jepang Level 1 atau sudah mempunyai kemampuan bahasa Jepang tingkat lanjutan. Selama membaca berpasangan, percakapan atau diskusi yang terjadi direkam ke dalam alat perekam, untuk kemudian dibuat protocol data. Dari protocol data tersebut dianalis proses yang terjadi ketika dilakukan kegiatan membaca.

Bahan bacaan yang digunakan oleh Tateoka adalah bahan bacaan yang bertema Jepang, tepatnya tentang larangan berburu burung di Taman Ueno.

Hasil penelitian ini adalah dengan melakukan peer reading pemelajar dapat saling mempelajari pengetahuan dan strategi membaca, tidak hanya satu orang mengajarkan pengetahuan ataupun strateginya secara searah, tetapi dua arah. Dengan kata lain terjadi hubungan mutual di antara ke dua pemelajar tersebut. Selain itu terlihat juga kegiatan dimana pemelajar mengevaluasi pemahamannya. Dengan masukan dari pasangannya pemelajar tersadar akan masalah yang dihadapi ketika membaca, membaca ulang kembali bacaan, serta memperbaiki pemahamannya, sehingga pemahaman pemelajar terhadap isi bacaan semakin mendalam.

Berdasarkan hasil dari penelitiannya ini dapat diperkirakan bahwa tidak hanya pemelajar dengan kemampuan level lanjutan, mahasiswa level menengah pun dapat memahami isi bacaan otentik apabila kegiatan membaca tersebut dilakukan berkelompok.

Fokus dari penelitian ini adalah pemahaman mahasiswa terhadap garis besar isi bacaan dan juga proses yang terjadi pada kegiatan membaca berkelompok dilihat dari mutual activity (aktivitas saling menguntungkan) dan prior knowledge (Pengetahuan yang didapat/dipunyai sebelumnya).

Target penelitian ini sama dengan target penelitian Tateoka yaitu pemelajar bahasa Jepang non-kanji, akan tetapi level kemampuan target penelitian ini berbeda dengan Tateoka. Seperti yang tertera di atas target penelitian ini adalah mahasiswa tingkat menengah. Perbedaan yang lainnya adalah penggunaan bahasa ibu sebagai media percakapan di dalam kelompok, karena mahasiswa tingkat menengah masih mempunyai keterbatasan dalam mengungkapkan pikiran dalam bahasa Jepang, dan perbedaan pada tema, karena penelitian ini memakai bahan bacaan yang berhubungan dengan Indonesia.

\section{METODE PENELITIAN}

Penelitian ini merupakan penelitian kualitatif dengan menggunakan metode protocol analisys. Protocol data yang dipakai dalam pelitian ini diambil dengan cara merekam percakapan mahasiswa ketika membaca bacaan dalam kelompok, untuk kemudian ditranskrip. Ketika menganalis protocol data yang digunakan, penulis menfokuskan pada hal-hal sebagai berikut:

1) Mutual activity seperti apa yang terlihat ketika mahasiswa membaca berkelompok?

2) Bagaimanakah penggunaan prior knowledge dalam usaha memahami isi bacaan?

Agar hasil analisis yang didapat valid, penulis membahas hasil analis dengan beberapa mahasiswa S2 dan S3 pendidikan bahasa Jepang beberapa kali sampai didapatkan kesamaan pendapat mengenai hasil analisis yang telah dilakukan.

Sumber data penelitian ini adalah mahasiswa program studi Jepang, Fakultas Sastra, Universitas Al Azhar Indonesia, yang terdiri dari mahasiswa tingkat 3 (4 orang), dan mahasiswa tingkat 4 (5 orang). Ke sembilan mahasiswa ini sudah lulus ujian kemampuan bahasa Jepang level 3, dan berada dalam level menengah (intermediate). 
Kuliah membaca berkelompok diadakan sebanyak 8 kali, 1 kali tatap muka dilakukan selama 60 menit, dan dilaksanakan pada bulan maret 2010.

Bahan bacaan otentik diambil dari artikel koran media elektronik. Tema bacaan yang dipakai adalah tentang masalah-masalah sosial yang dihadapi Indonesia. Alasan menggunakan tema yang berhubungan dengan Indonesia adalah agar mahasiswa dapat menggunakan prior knowledge yang dipunyainya untuk membantu pemahaman bacaan.

Ada 4 Tema bacaan yang dilakukan, akan tetapi yang dipakai dalam penelitian ini adalah tema tentang

『首都ゴミ戦争の現場見るブカシ市バンダル

・ゲバン』"Melihat Perang Sampah Daerah Ibu Kota, Bantar Gebang Bekasi". Alasan memilih tema ini sebagai bahan analisis adalah karena tingkat partisipasi mahasiswa baik dibandingkan dengan tema lainnya.

Alur kegiatan membaca adalah sebagai berikut:

1) Kegiatan pra-baca: mahasiswa membaca artikel berbahasa Indonesia dengan tema yang sejalan dengan artikel bahasa Jepang.

2) Penjelasan mengenai kosakata.

3) Pengenalan tema bacaan dengan meminta mahasiswa untuk mengingat garis besar isi artikel berbahasa Indonesia yang dibaca dan memperlihatkan gambar atau video yang berhubungan dengan tema bacaan.

4) Mahasiswa membaca artikel berbahasa Jepang berkelompok sambil menjawab pertanyaan di lembar kerja.

\section{HASIL DAN PEMBAHASAN}

\subsection{Dilihat dari Mutual Activity}

\section{1) Saling Mengajarkan Pengetahuan Bahasa}

Dari data percakapan mahasiswa, banyak terlihat aktivitas saling mengajarkan kanji, arti kosa kata, maupun maksud dari ekpresi bahasa Jepang yang dibaca. Saling mengajarkan kanji, kosakata, dll ini terlihat juga di dalam hasil penelitian Tateoka (2000).

\section{2) Saling Mengkonfirmasi Pemahaman Masing-Masing}

Dari protocol data mahasiswa banyak terlihat kegiatan saling mengkonfirmasi pemahaman antara anggota kelompok, Hal ini terlihat dalam contoh percakapan 1 di bawah ini. Di dalam percakapan contoh 1 mahasiswa membahas jawaban pertanyaan「バンダルゲバンはどんなところです か」(Tempat seperti apakah Bantar Gebang?) Di dalam percakapan ini terlihat, $M$ tidak percaya diri dengan pemahaman dirinya sendiri dan berusaha mengkorfirmasi ketepatan pemahamannya dengan bertanya kepada teman kelompoknya.

Contoh percakapan 1 :

1. M: Nomor satu apa kak? Tempat pembuangan sampah-sampah itu yah?

2. B: Tempat pembuangan sampah terakhir yang di pinggir kota Jakarta.

3. M: Pinggiran kota...約950 95セ、 何それ?世帯、4600ヒトが集まり (sekitar 950 per, apa itu? Keluarga, 4600 orang berkumpul)、empat ratus ehhh empat ribu...empat ribu enam ratus

4. B: Empat ribu enam ratus orang orang berkumpul di sana

5. T: Yang sekitar 950 keluarga

6. M: 950 keluarga itu berarti, 4600 orang itu?

7. T: Uum.

8. B: Uum. Dari 950 keluarga, dengan jumlah 4600 orang

9. T: 廃品(sampah), apa nih? 回収の仕事をしている。(bekerja mengumpulkan sampah)

10. M: 廃品回収 (mengumpulan sampah)、 ngumpulin sampah itu yah?

Yang perlu diperhatikan dalam contoh percakapan di atas adalah pertanyaan $M$ pada No.1 dan 6. Di sini $M$ terlihat mengkonfirmasi pemahamannya kepada teman kelompok. Dengan kegiatan membaca berkelompok, mahasiswa tidak hanya bertanya tentang pengetahuan bahasa yang tidak diketahuinya, tetapi juga saling mengkonfirmasi pemahaman masing-masing. Dalam contoh di atas M memonitor pemahamannya dan merasa ada ketidaksesuaian, dengan adanya teman dalam membaca $M$ dapat mengkonfirmasi langsung benar atau tidaknya pemahamannya dan dapat menyelesaikan masalah yang terjadi dalam membaca segera. Aktifitas saling mengkonfirmasi pemahaman dengan segera ketika mendapatkan masalah membaca ini merupakan keuntungan ketika membaca berkelompok karena bisa langsung menggunakan resource yang ada di depan mata, yaitu teman satu kelompok. Dengan mengkonfirmasi kepada teman, masing-masing 
mahasiswa dapat menyadari sampai dimana pemahamannya terhadap isi bacaan.

\section{3) Perbaikan Pemahaman Akibat Kesadaran Anggota Group Lainnya.}

Dari contoh percakapan 2 , terlihat adanya situasi dimana mahasiswa memperbaiki pemahaman sebelumnya dikarenakan anggota kelompok yang lainnya tersadar akan kata kunci yang penting di dalam bacaan.

Contoh percakapan 2 adalah percakapan yang terjadi ketika mahasiswa membahas jawaban pertanyaan tentang「エカさんはなぜ廃品回収の 仕事をしていますか」(Mengapa Eka bekerja sebagai pemulung?).

\section{Contoh percakapan 2:}

1. M: Alesan, alesannya dia tinggal di tempat ini.に住む理由を話した(bicara alasan tinggal kepada), alasan dia tinggal di tempat ini? Kebersihan lingkungannya, paling buruk yah?

2. T: Iya, 最悪 (paling buruk)

3. B: Ya, karena meskipun di sana apasih karena tempatnya itu,

4. T: Semua maksudnya?

5. B: Kalau dia sih di sini dijelasin, walaupun di sana lingkungannya kotor, banyak polusi, tapi dia di sana mendapatkan...

6. M: Uang. ここはゴミを売って、 (di sini jual sampah)

7. B: Ada harta karun, maksudnya bisa menjual sampah seperti....

8. M: キン、カネ?が、何?、かせぐ( kin, uang? $g a$, apa?, mendapat) yah? 稼げる(bisa mendapatkan) gitu?kak ini 稼ぐ(mendapatkan) bukan sih?

9. B: Ini mendapatkan kan?

10. T: Bukan ini yang kemaren.

11. M: 稼ぐ(mendapatkan)、 bener

12. B: Mendapatkan, bisa mendapatkan...

13. M: 稼げる、え一、宝、宝何? 宝、宝、 (bisa mendapatkan, ee, harta karun, harta karun apa? harta karun, harta karun) harta karun,

14. T: 宝の山 (gunung harta karun)

15. M: の・・・冷蔵庫やテレビだって買える (no....lemari pendingin, televisi, dll., pun bisa beli) uum ada TV sama kulkas gak terpakai gitu, yang bisa dijual?

16. T: 買える! (Bisa beli!)

17. M: Eh, bisa dibeli?bisa membeli!

18. B: Mereka bisa membeli dengan mengumpulkan sampah yang dari Bantar Gebang itu.

19. M: Owalahh

20. B: Dengan itu dia bisa jadi beli TV, sama kulkas. Itu alasannya dia, kenapa dia tinggal di situ, walaupun itu tempatnya kotor.

21. M: Ohh, jadi dia tinggal ditempat itu, siapa tahu dia masih menemukan sesuatu yang berharga, terus dijual sama dia buat dapetin duit buat beli TV sama...

22. B: Dia kan ditanya, kenapa sih dia istilahnya tinggal disitu, dia jawab meskipun disana kotor.

23. M: Meskipun kotor setengah mati..

24. B: He eh tapi dengan ehh walaupun seperti itu dia dapat membeli televisi dan kulkas dengan menjual barang-barang yang ada di sana.

Pada awal contoh percakapan 2, pemahaman dari B dan $M$ tidak sesuai dengan bacaan. Akan tetapi berkat $\mathrm{T}$ yang menyadari bahwa kata kunci dari kalimat yang sedang dibaca adalah「買える」(bisa beli) (No.16 T), B dan M menyadari kesalahan pemahaman masing-masing, mengulang membaca kalimat, dan memperbaiki pemahaman. Melalui percakapan di atas, akhirnya kelompok ini berhasil menangkap maksud dari kalimat yang sedang dibaca. Pemahaman B dan $\mathrm{M}$ yang sebelumnya adalah「ゴミの山の中か

ら冷蔵庫やテレビを見つけることができるから 、それを売ってお金を稼ぐ」（karena bisa menemukan televisi, lemari pendingin, dll, mereka menjual itu, dan mendapatkan uang), menjadi「バンダルゲバンで回収したゴミを売っ て、そのお金で泠蔵庫やテレビが買える。」

(Mereka menjual sampah yang dikumpulkan, dan membeli televisi, lemari pendingin, dll, dengan uang itu).

Perbaikan pemahaman ini terjadi disebabkan karena adanya teman membaca. Apabila kegiatan membaca dilakukan sendiri, B mungkin tidak menyadari kesalahan pemahaman yang ada pada dirinya, dan akan mempengaruhi pemahaman bacaan secara keseluruhan. Di dalam contoh percakapan 2 ini mahasiswa dapat saling memonitor pemahaman masing-masing, menyadari perbedaan pemahaman masing-masing untuk selanjutnya mengevaluasi pemahaman sebelumnya sehingga terbentuklah pemahaman yang baru, dan hasil akhirnya adalah terciptanya pemahaman tentang isi bacaan yang mendalam. 


\subsection{Dilihat dari Penggunaan Prior Knowledge}

Pengunaan prior knowledge bisa terlihat dalam contoh percakapan 3 berikut.

Dalam contoh percakapan ini mahasiswa berhasil memahami bacaan dengan menggunakan prior knowledge.

Contoh percakapan 3 ini membahas jawaban pertanyaan mengenai 「バンダルゲバン で廃品回収の仕事をしている人はどのぐらいで すか」(Berapa orang yang melakukan pekerjaan pemulung di Bantar Gebang?). Jawaban yang tertera di bacaan adalah 「4600人」(4600 orang), dan mahasiswa hanya perlu mengambil informasi ini sebagai jawaban, tanpa harus berpikir panjang. Akan tetapi mahasiswa yang menjadi target dalam penelitian ini mempertanyakan kebenaran angka "4600 orang" yang tertulis di dalam bacaan dan mencoba mengerti maksud dari angka 4600 orang tersebut dengan menggunakan prior knowledge.

Contoh percakapan 3:

1. Z: Mengumpulkan barang-barang, pekerjaan mengumpulkan barang-barang bekas

2. L: Seberapa, kan「どのぐらい」よね。 ("berapa banyak" kan yah)

3. Z: Seberapa, 「どのぐらい」 (“berapa banyak"), seberapa banyak orang-orang yang mengumpulkan

4. L: Iya sih. Terus mereka tuh orang-orang yang seperti apa?

5. Z: Apa ini yah? 4600 jiwa ini?

6. L : Tapi emang 4600 jiwa itu semuanya?

7. Z: Kan anaknya, kan ada anak kecil, orang dewasa, orang tuanya mungkin. Wanita aja ngumpulin sampah.

8. L : Berarti segitu orangnya.

9. Z: Berarti misalnya dalam satu rumah ada 4 orang. Empat-empatnya ngumpulin sampah.

10. L: Iyah sih.

11. Z: Iyah, kan mereka di rumah mau ngapainkan? Pendapatan mereka satu-satunya dari situ.

12. L : Uum, bener bener bener.

Yang menjadi perhatian pada percakapan 3 di atas adalah pertanyaan yang diucapkan L pada No. 6 . Pertanyaan ini muncul karena ada keraguan akan besar angka yang tertera di dalam bacaan, yaitu 4600 orang. Ketika membaca kalimat yang mengandung informasi tentang jumlah pemulung di Bantar Gebang yang mencapai 4600 orang, timbul pertanyaan mengenai kebenaran jumlah yang tertera dalam bacaan.

Kondisi dimana siswa bisa mempunyai pertanyaan tentang informasi yang ada di bacaan, manurut Mori dalam penelitiannya tahun 2000, dikatakan sebagai "Membaca sambil berdialog". "Membaca sambil berdialog" bagi pemelajar bahasa Jepang tingkat lanjutan sangat sulit dilakukan apalagi bagi pemelajar tingkat dasar dan menengah, dan merupakan ciri dari pembaca penutur asli. Dalam penelitian Mori, pemelajar tingkat dasar dan menengah, hanya menerima informasi searah dari bacaan dan terkungkung dalam bacaan. Hal ini bertentangan dengan hasil penelitian ini, dalam penelitian ini mahasiswa bertanya tentang isi bacaan seolah-olah berdialog dengan bacaan yang dibaca.

Hal yang menyebabkan mahasiswa tingkat menengah dapat membaca seperti di atas adalah karena tema bacaan yang berhubungan dengan kehidupan mahasiswa dan juga karena kegiatan pra-baca. Dengan kegiatan pra-baca maka mahasiswa mendapatkan pengetahuan yang berkaitan dengan tema. Penggabungan antara informasi yang didapat di dalam bacaan dan prior knowledge inilah yang menimbulkan pertanyaan seperti di atas.

Selain itu penggunaan bahasa ibu ketika berdiskusi dengan anggota kelompok juga berpengaruh Dengan menggunakan bahasa ibu akses untuk menggunakan prior knowledge menjadi sangat mudah karena tidak adanya beban bahasa.

Di dalam contoh percakapan 3 di atas perlu juga diperhatikan pernyataan No.7,9,11 yang dilakukan oleh Z. Untuk menjawab pertanyaan dari L, Z menggunakan prior knowledge. Di dalam artikel berbahasa Indonesia dan bacaan bahasa Jepang dikatakan bahwa tidak hanya anak-anak, laki-laki dan wanita pun ikut mengumpulkan sampah, dari sini $\mathrm{Z}$ membayangkan bahwa seluruh anggota keluarga menjadi pemulung. Kemudian pernyataan $\mathrm{Z}$ bahwa para pemulung yang tinggal di Bantar Gebang hanya mendapatkan penghasilan dari mengumpulkan sampah dan tidak ada yang dilakukan apabila hanya tinggal di rumah saja, juga merupakan hasil dari usaha untuk memahami isi bacaan dengan menggunakan prior knowledge.

Dari sini dapat dikatakan bahwa mahasiswa berusaha untuk membuat pemahaman yang benarbenar dimengerti oleh dirinya sendiri. Pemahaman 
yang seperti ini menurut Ban (2010) disebut dengan 「内的説得力がある言葉」 atau pemahaman yang benar-benar dipahami pembaca, yang muncul dari diri pembaca itu sendiri dengan mengaitkan isi bacaan dengan pengalaman dan pengetahuan yang sudah dipunyai.

Apabila kita melihat contoh percakapan 3 di atas mahasiswa tidak hanya memahami 「4600人」 (4600 orang) sebagai sebuah angka akan tetapi juga latar belakang yang melingkupi angka tersebut. Dengan kata lain dalam pemahaman mahasiswa terhadap kalimat 「4600人」(4600 orang) mencakup pemahaman bahwa 4600 orang yang berkumpul di Bantar Gebang terdiri dari keluargakeluarga. Keluarga-keluarga tersebut melibatkan seluruh anggota keluarganya untuk bekerja. Karena di sana terlihat anak-anak, pria, wanita, dll., yang mengumpulkan sampah. Dan alasan semua anggota keluarga bekerja adalah karena tidak ada pekerjaan lain yang dapat dilakukan, dan penghasilan mereka hanya dari memulung.

\section{KESIMPULAN}

Dilihat dari hasil lembar kerja dan percakapan mahasiswa maka dapat dikatakan bahwa mahasiswa dapat menangkap garis besar dari isi bacaan.

Dari sudut pandangan mutual activity yang terjadi, terlihat adanya kegiatan saling mengajarkan pengetahuan berbahasa antara anggota kelompok, saling mengkonfirmasi pemahaman masing-masing dan adanya perbaikan pemahaman yang disebabkan dari informasi yang didapat dari anggota kelompok.

Salah satu faktor penyebab mahasiswa tingkat menengah bisa menangkap garis besar isi bacaan adalah penggunaan bahasa ibu sebagai media berdiskusi tentang bacaan yang dibaca. Faktor ini tidak ada di dalam penelitian Tateoka (2000). Dengan menggunakan bahasa ibu sebagai media diskusi mahasiswa bisa dengan bebas melakukan tanya jawab, dan mengkonfirmasi pemahamannya. Di samping itu juga, mahasiswa dapat mengeluarkan semua pikirannya tanpa batas ketika mendengarkan pemahaman dari angota kelompok, sehingga dapat menyadari kesalahan pemahaman seperti yang terjadi pada contoh percakapan 2 . Apabila diskusi dilakukan dalam bahasa Jepang, ada kemungkinan tidak terjadi karena kemampuan bahasa Jepang mahasiswa tingkat menengah masih terbatas.

Hal ini seperti ini juga terlihat pada penelitian Yanjun (2010). Dalam penelitian Yanjun dengan menggunakan bahasa ibu sebagai media ketika berdiskusi di dalam kegiatan menerjemahkan bacaan bahasa Jepang, mahasiswa bisa mengungkapkan pendapatnya dan melakukan tanya jawab dengan bebas sehingga hasil dari kegiatan tersebut baik. Menurut Yanjun (2010), melalui penggunaan bahasa ibu, mahasiswa dapat dengan mudah menggunakan prior knowledge yang didapat dengan media bahasa ibu dan dapat dengan mudah untuk membantu memahami bacaan.

Prior knowledge setiap mahasiswa berbeda-beda tergantung lingkungan pendidikan, kehidupan, dll, dari mahasiswa tersebut. Ketika memahami sebuah bacaan masing-masing mahasiswa perlu membangkitkan prior knowledge dan dari sana membuat pemahamannya sendiri. Seperti yang terlihat dalam contoh percakapan 3 , pemahaman mahasiswa pada jumlah pemulung di Bantar Gebang tidak terhenti pada angka yang tertera di dalam bacaan (4600 orang), tapi juga mencakup hal-hal yang melatarbelakangi angka tersebut Dengan kata lain bahwa mahasiswa memahami angka tersebut sebagai apa yang dikatakan Ban (2010) dengan「内的説得力がある言葉」 (pemahaman yang benar-benar dipahami pembaca, yang muncul dari diri pembaca itu sendiri dengan mengaitkan isi bacaan dengan pengalaman dan pengetahuan yang sudah dipunyai).

Dengan demikian saran yang dapat diusulkan untuk pengembangan kemampuan menbaca bahan acuan otentik pemelajar non-kanji tingkat menengah adalah dengan melakukan membaca berkelompok. Dengan membaca berkelompok maka akan timbul mutual activity dimana mahasiswa saling menggunakan resource yang dipunyai sehingga dapat saling membantu pemahaman masingmasing. Penggunaan bahasa ibu dalam dialog mengenai isi bacaan juga penting, karena dengan menggunakan bahasa ibu, mahasiswa dapat lebih bebas mengeluarkan pikiran dan mengakses serta menggunakan prior knowledge untuk membantu pemahaman, dengan pertimbangan bahwa kemampuan bahasa Jepang tingkat menengah masih terbatas. Selain itu bimbingan membaca bahan acuan otentik pada tingkat awal sebaiknya menggunakan tema yang berhubungan dengan kehidupan dari mahasiswa itu sendiri sampai mahasiswa terbiasa dengan bahan bacaan otentik. 
Karena dengan menggunakan tema yang dekat dengan kehidupan mahasiswa dapat membantu siswa dalam memahami isi bacaan karena mahasiswa sudah mempunyai prior knowledge tentang tema yang bersangkutan.

\section{DAFTAR ACUAN / PUSTAKA}

[1] Okazaki, Hitomi. "Naiyojushi no Nihongo Kyoiku Daigaku no Baai." Journal of Tokyo Foreign Language University, 49, 227-244. 1994.

[2] Mori, Masko. "Bokokugo oyobi Gaikokugo toshite no Nihongo Tekisuto no Dokkai - Think-aloud Ho niyoru 3 tsu no Casestudy." Journal of Sekai no Nihongo Kyouiku, 10, 57-72. 2000.

[3] Tateoka, Yoko. "Katei ni Okeru Gakushushakan no sogosayo- Peer Reading no Kanosei o Megutte." Bulletin of Japanese Research Center, Amerika Canada University, 23, 25-50. 2000.
[4] Tateoka,Yoko.."Taiwatekimondaiteikikyodogakush u no Kanosei - Peer Reading no Jissen kara no Kento." Bulletin of Foreign Student Education, Tokai University, 24, 37-47. 2004.

[5] Tateoka, Yoko.'Hitori de yomukoto kara Peer Reading e - Nihongo Gakushusha no Dokkai Katei to Taiwateki Kyodo Gakushu." Tokai University Press. 2005.

[6] Taniguchi, Sumiko. "Shikokatei o Dashiau Dokkai Jugyou:Gakushusha Strategy no Kansatsu.” Journal of Japanese Education, 75, 27-49. 1991.

[7] Ban, Hyonhi. "Jizokukanosei Onsei Kyoiku Toshite no Peer Monitoring Katsudo - Kiyu Noryoku no Hakki o Toshite Kochikusareru Hatsuon Kijun" Journal of Language, Culture, and Japanese Education, 40, 1-10. 2010.

[8] Yan, Jun. "Chugoku no Daigaku no Nihongo Senkoshukankamoku e Group Work no Teian Gengo Seitai no Hozen no Kanten kara-“" doctoral thesis, Ochanomizu University. 2010. 